\title{
NOSSA CASA ESTÁ CAINDO... E AGORA, VANESSA? CAPITALISMO, DECOLONIALIDADE E FUTUROS RE-IMAGINADOS
}

\author{
OUR HOUSE IS FALLING DOWN... WHAT NOW, VANESSA? \\ CAPITALISM, DECOLONIALITY AND REIMAGINED FUTURES
}

\author{
Vanessa de Oliveira Andreotti ${ }^{\star}$ \\ Jhuliane Evelyn da Silva** \\ Clarissa Menezes Jordão ${ }^{* *}$
}

\begin{abstract}
RESUMO
Fruto de diálogos estabelecidos ao longo de algum tempo, a presente entrevista intenta contribuir para ampliar os horizontes da pesquisa em Linguística Aplicada no Brasil e das pesquisas fundamentadas em quadros de referência críticos e decoloniais, que colocam em xeque a modernidade/colonialidade, bem como noções de progresso, desenvolvimento, verdade, certeza e educação fundadas na separabilidade que privilegia o ser humano em relação a todos os outros seres. É nessa tônica que a professora Vanessa de Oliveira Andreotti, titular da Cátedra de Pesquisa Canadense em questões relacionadas à raça, globalização, desigualdades e transformações sociais na educação, nos convida a dar um passo atrás: não para enxergar o "verdadeiro" cenário e analisar as consequências da globalização, mas para tentarmos entender os padrões históricos e sistêmicos de reprodução dessas desigualdades e assim vislumbrar ou mesmo criar possibilidades outras de coexistência no planeta. O escopo da entrevista, neste sentido, insere a Linguística Aplicada num universo amplo que inclui nossas bases ontoepistemológicas na percepção do que seja construir conhecimento e fazer ciência num processo de ampliação de possibilidades de leitura de si, do outro e do mundo. Palavras-chave: modernidade/colonialidade; interrupção; futuros alternativos; cosmologias indígenas; responsabilidade visceral.
\end{abstract}

\section{ABSTRACT}

As a result of dialogues established for some time now, this interview aims to contribute to broaden the horizons of both research in Applied Linguistics in Brazil and research based on critical and decolonial scholarships. These perspectives question modernity/ coloniality, as well as notions of progress, development, truth, certainty, and education, which are based on a separability that privileges the human being over all other beings. Building on this, Professor Vanessa de Oliveira Andreotti, who holds a Canada Research Chair in Race, Inequalities and Global Change, invites us to take a step back, but not to see the "real" scenario and analyze the consequences of globalization. Instead, the invitation is to try to understand the historical and systemic patterns of reproduction of inequalities and thus to envision or even create other possibilities for coexistence on the planet. The interview, then, positions Applied Linguistics in a broad universe that includes our ontoepistemological bases in the perception of what it means to build knowledge and to do science in a process of expanding the possibilities of reading oneself, the other, and the world. Keywords: modernity/coloniality; interruption; alternative futures; Indigenous cosmologies; visceral responsibility.

\section{INTRODUÇÃO}

No final de 2018 convidamos Vanessa de Oliveira Andreotti, professora titular da Cátedra de Pesquisa Canadense em Raça, Desigualdades e Transformações Globais, para uma conversa. Nascida no Brasil e aqui graduada em Letras Inglês pela Universidade Federal do Paraná, ela alçou voo e foi continuar sua carreira acadêmica na Inglaterra, na Irlanda, na Nova Zelândia, na Finlândia e no Canadá, onde hoje atua como professora associada efetiva do Departamento de Estudos Educacionais da Faculdade de Educação, na Universidade de British Columbia em Vancouver. Autora de Actionable Postcolonial Theory in Education, livro que reúne seus dez primeiros anos de pesquisa, ela também organizou The Political Economy of Global Citizenship Education e co-organizou Postcolonial Perspectives on Global Citizenship Education com o professor Lynn Mario T. Menezes de Souza (USP), para destacar alguns títulos. Em produção robusta de artigos autorais e em coautoria com membros do coletivo Sinalizando Rumo a Futuros Decoloniais, do qual é cofundadora, Vanessa tem trabalhado junto a educadores, ativistas, artistas e pesquisadores em torno de questões que lidam com violência sistêmica, desigualdades, meio ambiente e o "fim do mundo" como ele se apresenta hoje.

\footnotetext{
* Canada Research Chair \& Associate Professor da Universidade da Colúmbia Britânica, Canadá. vanessa.andreotti@ubc.ca Orcid: https://orcid.org/0000-0003-1608-2488

** Doutoranda em Letras pela Universidade Federal do Paraná (UFPR),Curitiba, PR, Brasil. anecomjesus@gmail.com Orcid: https://orcid.org/0000-0003-0143-7944

*** Professora sênior no Programa de Pós Graduação em Letras da Universidade Federal do Paraná (UFPR), Curitiba, PR, Brasil. clarissamjordao@gmail.com

Orcid: https://orcid.org/0000-0003-3558-5603
} 
Percebemos o trabalho de Andreotti como de grande importância para nos ajudar a pensar sobre nossos tempos. Tempos pandêmicos. Por maior que seja o lugar-comum ocupado por essa frase ultimamente, é preciso dizê-la - e escrevê-la. Não há como esquecer o impacto que a pandemia tem tido não apenas literalmente em nossas vidas, mas também em termos do que ela tem nos feito refletir sobre nossas posições no mundo. Pensamos sobre o que podemos fazer quando nos vemos em nossas relações pessoais, profissionais, ontoepistemológicas, enfim: pensamos sobre o que podemos fazer, porque o não fazer é também um fazer. Neste pano de fundo, pusemo-nos a escrever esta introdução, refletindo sobre a entrevista concedida pouco antes de a pandemia ser declarada pela Organização Mundial da Saúde. Não sabíamos, na época da entrevista, que em breve viveríamos tempos tão distópicos e tão desesperadores quanto os em que estamos agora. Não sabíamos com que intensidade as palavras de Vanessa Andreotti em resposta a nossas inquietações reverberariam em nós num futuro muito próximo. Pensamos naquele momento, enquanto elaborávamos as questões que faríamos nesta entrevista, em nossa posição como linguistas aplicadas diante de um mundo prépandêmico que já nos parecia estar próximo do fim, ou pelo menos do fim de uma era capitalista que parecia não estar mais dando conta de nossos modos de vida extrativistas (SOUSA SANTOS, 2020) e autocentrados. Estávamos num túnel sem luz e sem fim, solidarizadas com outros professores e alunos sem esperança, num sistema educacional público que vinha sendo golpeado constantemente, bombardeado por discursos desmoralizantes e ofensivos, que questionavam a qualidade do ensino e da formação de docentes e discentes nas escolas, institutos e universidades federais do país. Era dezembro de 2019.

Em meio a essa escuridão, ainda antes da pandemia, perguntamos a Vanessa Andreotti sobre questões voltadas à diversidade, em contraponto ao discurso político negacionista que circulava no Brasil ignorando a existência de racismo no país, por exemplo; também nos movia a indignação diante dos ataques físicos e aos direitos de pessoas negras e da comunidade LGBTQI+, sem contar o que sofriam as mulheres que tinham inclusive a lei Maria da Penha desrespeitada flagrantemente e com o apoio de setores da sociedade civil organizada (DA SILVA; SOTERO, 2020). Refletimos com ela sobre como os discursos que circulam entre nós e nos constituem podem estar relacionados à colonialidade que vivemos, e como podemos nos inspirar e promover a interrogação e interrupção de discursos (incluindo aí práticas) excludentes e violentos. Baseamo-nos no que diz Deborah Cameron ao afirmar que "o uso da língua é em si mesmo uma prática social" ${ }^{\prime \prime}(1997$, p. 64) para pensarmos sobre o papel da linguagem em nossas vidas, sendo ela foco de estudos recentes na interface de áreas do conhecimento como Antropologia Linguística, Sociolinguística e Linguística Aplicada, todas tomando por base a concepção de linguagem como prática social (OLIVEN, GARCEZ, 2020). Andreotti dialoga com essa concepção ao criticar a separação moderna fundante de nossas ontoepistemologias, a distinção entre razão e emoção (separação que relacionamos com a distinção fundante da linguística tradicional, ou seja, entre língua e fala, pensamento e linguagem). Tal separação, integrante da separabilidade classificatória e hierarquizante do pensamento moderno, segundo Andreotti, nos coloca num círculo vicioso que faz nossos "parâmetros de inteligibilidade" ficarem presos numa "gramática de pensamento que localiza o alicerce do ser no saber" (Andreotti, na resposta à pergunta 6 desta entrevista). Daí a facilidade com que priorizamos o racional, o descritivo, o masculino diante de seus extremos binários, o emocional, o interpretativo, o feminino. E desse binarismo hierarquizado parecem proceder séries e séries de discriminações, preconceitos, violências, exclusões, invisibilizações que projetam para o outro lado da linha abissal tudo aquilo que é o outro da modernidade (SOUSA SANTOS, 2019).

Conversamos também sobre diferenças linguísticas e culturais, sobre violência epistêmica, sobre as práxis decoloniais desenvolvidas por comunidades como o coletivo Sinalizando Rumo a Futuros Decoloniais, explorando com ela possibilidades de práxis educativas na perspectiva de estudos decoloniais como os do grupo Modernidade/ Colonialidade, pensando a partir da ideia das Epistemologias do Sul, de Boaventura de Sousa Santos.

O trabalho de Andreotti, embora não faça relações explícitas com os trabalhos da antropologia linguística crítica de Heller ou de Cameron, aproxima-se deles em sua concepção de educação, colocando-se ao lado de reflexões feitas também pelo grupo de (socio-antropo)linguistas aplicados/críticos brasileiros que participam desse dossiê, por exemplo, ao se debruçarem sobre a linguagem como espaço ideológico, social, cultural e, portanto, sempre conflituoso, político, situado e enunciativo (BAKHTIN, 2010, 2016). Mas não apenas nesse sentido: também, como se poderá observar na leitura da entrevista, as posições e preocupações de Andreotti têm relação com a importância de se pensar em termos do que Freire designou como "inéditos viáveis", e que a Sociolinguística

1. No original: "language-using is a social practice in its own right". 
crítica tem colocado como central em suas preocupações. Para Freire (2014), esperançar é fundamental e nos leva a devisar algo que ainda não vimos, mas que idealizamos como desejável para um mundo melhor, um mundo que possa tratar as diferenças com respeito sem silenciá-las, sem projetá-las para o outro lado da linha abissal que a modernidade/colonialidade construiu (SOUSA SANTOS, 2007). E a linguagem ocupa papel fundamental neste mundo.

Nesse sentido também Heller e McElhinny (2017, p. xv) apontam para a necessidade de que a Sociolinguística conceba a centralidade da linguagem não apenas na construção da colonialidade, mas também na "cura do trauma entretecido pelos instrumentos do colonialismo e do império" ${ }^{2}$, processo que se dá numa Sociolinguística preocupada com questões de desigualdade social, uma Sociolinguística e uma Linguística Antropológica que, segundo elas, "se recusem a engajar-se em processos que reproduzem males antigos, mesmo que o façam de modos novos" (HELLER; McELHINNY, 2017, p. xv). A linguagem assim concebida, bem como as disciplinas acadêmicas que a estudam, estão entremeadas de colonialidade, envolvidas até o pescoço com o capitalismo e o colonialismo, e precisam se reinventar para ser, ao mesmo tempo, um espaço de cura da violência por eles perpetrada. É o pharmakon, veneno e remédio simultaneamente (DERRIDA, 2005).

A Sociolinguística construída e defendida por Heller e McElhinny (2017), assim como a Linguística Aplicada made in Brasil (JORDÃO, no prelo) e as reflexões que Vanessa Andreotti promove em seu trabalho, percebem a linguagem como enredada em questões sociais, políticas, ideológicas e, portanto, como indissociável delas e fundamental para que possamos "reimaginar futuros diferentemente" (HELLER; McELHINNY, p. 257), ou seja, mudar não apenas o conteúdo, mas também os termos da conversa (MIGNOLO, 2017). Tal reimaginar, uma questão de sobrevivência quando nossa casa (a modernidade e o capitalismo) parece estar ruindo e descortinando uma sociedade planetária retrógrada, conservadora, intolerante e cruel, passa necessariamente pelos estudos da linguagem na perspectiva adotada no presente dossiê. E será encontrado novamente nessa entrevista, que propõe um exercício de reimaginar o mundo com base em práticas já acontecendo em espaços diversos, acadêmicos e não acadêmicos, cuja existência nos serve de inspiração e nos enche de esperanças de que um outro mundo seja possível.

Sem mais preâmbulos, vamos então ao exercício de reimaginação e esperança proposto por Vanessa Andreotti.

1. Atualmente tem havido um grande interesse no que diz respeito à decolonialidade. No Brasil não é diferente. Não é raro escutar sobre a necessidade de decolonizar as diversas disciplinas, ou ainda de incluir questões de raça, gênero, linguagem como fundamentais nas preocupações da decolonialidade. Como você vê esse interesse?

Vanessa Andreotti: Por um lado, esse interesse é superpositivo. Por outro lado, estamos vivendo um período de grande liquidez discursiva (de alta instabilidade dos significados) e embriaguez afetiva (de alta carga emocional coletiva incontida), ao mesmo tempo em que também vivemos um período em que o consumo virou o modo de relação com o mundo: não só o consumo material, mas também o consumo de conhecimentos, de experiências, de relações e de pessoas. Assim, as pessoas não só usam os significados de uma maneira fluida (o que pode ser interessante), mas também condicionada a diferentes tipos de conveniências relacionadas a projeções, investimentos e apegos afetivos. Nesse contexto, a decolonização vira um slogan que é muitas vezes mobilizado para reproduzir desejos e assegurar direitos que são calcados, ironicamente, na própria colonialidade e no colonialismo. Por exemplo, aqui no Canadá a decolonização virou moda e pode significar desde a reestruturação do posicionamento das cadeiras na sala de aula de quadrado para círculo, quanto a pauta de abolição da própria universidade. Quando alguém não está satisfeito com alguma coisa, já vem a vontade de substituição "decolonial" por algo que se remete a preferências pessoais que são justificadas de modo político. No meu grupo de estudos, conversamos bastante sobre essas tendências e sobre a dificuldade de levantar essas questões e interromper nossos próprios alicerces ontológicos, incluindo desejos (por conforto, conveniência, certezas, controle, autoridade, autonomia irrestrita, segurança) enraizados na colonialidade e viabilizados pelo colonialismo.

2. No original: "beal the trauma wrought by the instruments of colonialism and empire".

3. No original: "reimagining futures differently". 
2. Como os estudos sobre decolonialidade conduzidos por você e pelo coletivo Sinalizando Rumo a Futuros Decoloniais (SRFD) convergem, divergem e diferem dos estudos propostos pelos membros do grupo Colonialidade/Modernidade e pelas Epistemologias do Sul promovidas por Boaventura de Sousa Santos?

Vanessa Andreotti: No nosso coletivo (ANDREOTTI et al., 2019) utilizamos muitos aspectos da crítica do grupo Colonialidade/Modernidade e temos muito respeito por esse trabalho. Entretanto, enquanto a maioria dos críticos da modernidade associa o colonialismo à ocupação expansionista de terras e à subjugação de povos, muitos povos indígenas veem essas manifestações de violência como sintomas de um modo mais profundo e mais antigo de violência que acontece nos reinos ontológico e metafísico - o reino do "existir". Essa violência mais profunda e mais antiga é a sensação imposta de separação entre nós e o dinâmico metabolismo vivo que é o planeta. Esse senso de separação imposto, ou separabilidade, é mais antigo do que a própria modernidade. Alguns localizam suas origens nas tradições abraâmicas que apresentam uma entidade divina masculina semelhante à humana, presenteando a natureza a humanos escolhidos como um recurso a ser administrado. Outros focam em como a separabilidade se manifestou na Grécia, quando a filosofia grega mudou das tradições orais para a tecnologia da escrita, substituindo o conhecimento contextual por uma busca por significados universais definidos e documentados por certos humanos. Essa mudança tecnológica contribuiu para a percepção de que as árvores e a terra não podiam mais nos ensinar nada de valor e que o progresso humano está nas cidades. Isso é ilustrado por uma passagem de um dos diálogos platônicos, Fedro, em que Platão documenta as palavras de Sócrates: "... adoro aprender, e as árvores e o campo aberto não me ensinam nada, enquanto os bomens da cidade o fazem". (PLATÃO, 2000, p. 19).

A separabilidade é baseada no excepcionalismo humano, que é a ideia de que os humanos são uma espécie especial superior que merece estar em posição de conquistar, possuir e controlar o ambiente natural. O excepcionalismo humano é também a base do antropocentrismo, que coloca os humanos no centro e como as entidades mais importantes do mundo. $\mathrm{O}$ excepcionalismo humano e o antropocentrismo têm sido frequentemente justificados com base na capacidade dos humanos de raciocinar, entendida como a capacidade de conscientemente dar sentido à realidade e de aplicar a lógica para adaptar e justificar decisões. Essa parte da separabilidade não é prioridade para o grupo Colonialidade/Modernidade ou para as Epistemologias do Sul, porém existem várias interfaces de complementaridade entre o trabalho do coletivo SRFD e essas áreas de estudo.

3. Seus últimos trabalhos focam na impossibilidade da continuação da modernidade como ela se encontra a partir da metáfora da casa que a modernidade construiu, com um alicerce de separabilidade, paredes de apoio à razão e ao Estado-nação e um telhado de capitalismo global, isto é, uma casa que apesar dessas bases (ou justamente por causa delas) está caindo - ou já caiu (ANDREOTTI $;$ STEIN; SUSA, 2019). Como vocês têm atuado diante desse cenário?

Vanessa Andreotti: Temos tentado mapear respostas a essa "casa caindo" em vários contextos. Iniciamos esses mapeamentos bem antes da pandemia de covid-19, que evidenciou o problema estrutural da casa. Aqui também o trabalho do coletivo se diferencia de outros grupos de estudo: não estamos focados na substituição da casa por outra estrutura já conhecida, mas no tratamento paliativo da estrutura vigente, em que são os ensinamentos da queda da própria casa que vão amadurecer e direcionar as reconfigurações intelectuais, afetivas e relacionais do próximo sistema viável (porém não imaginável de dentro da casa). O contexto covid-19 também ajudou a abrir espaço para tópicos relacionados a colapsos ambientais e sociais que eram mais difíceis de abordar antes da pandemia: as pessoas estão um pouco mais preparadas para conversar sobre as consequências da violência e a insustentabilidade da modernidade. Nosso último experimento pedagógico é uma simulação de um processo global de construção de um projeto político pedagógico em 2048, após 20 anos de desastres sociais e ambientais e 10 anos de recuperação e reabilitação da humanidade (https://youtu.be/2rEAY3eMbNQ? $\mathrm{t}=777$ ).

Outro experimento recente foi a elaboração coletiva do texto "A preparação para o fim do mundo que conhecemos" (https://www.opendemocracy.net/en/oureconomy/preparing-end-world-we-know-it/). Esse texto oferece ensinamentos indígenas que afirmam que se abordarmos o potencial, probabilidade ou inevitabilidade do colapso de nosso sistema atual com maturidade relacional, sobriedade e responsabilidade, teremos a oportunidade de curar nossas relações e desequilíbrios afetivos e de aprender a coexistir de maneira mais responsável uns com os outros e com a Terra. 
4. Como podemos lidar com as violências promovidas pelo projeto colonial, como podemos ir além do questionamento sobre nossos quadros de referência informados justamente pela modernidade/colonialidade? Conhecer e questionar o projeto moderno/colonial são práticas suficientes para diminuir a sua violência?

Vanessa Andreotti: Sousa Santos nos chama a atenção para o fato de que o pensamento moderno é abissal porque cria linhas de inteligibilidade e existência; assim, de um lado dessa linha abissal existe o conhecimento que se vê como universal e que não percebe que é limitado, e do outro lado existem outros modos de existência que são registrados pela modernidade como inferiores ou inexistentes (porque não cabem na ontoepistemologia moderna). Sousa Santos critica a linha abissal e o epistemicídio que ela provoca. Existem duas respostas a essa análise. A primeira resposta é a de que precisamos de um pensamento que não gere essas linhas - um pensamento pós-abissal para podermos aprender com outras epistemologias, como as Epistemologias do Sul e/ou as Epistemologias Indígenas. O problema aqui é que, se tentarmos nos engajar com outras visões de mundo a partir de uma crítica epistemológica apenas, esse engajamento ainda vai estar calcado na onto-metafísica da modernidade. A onto-metafísica da modernidade/ colonialidade é uma maneira de existir definida pela linguagem e pela razão (na qual o "ser" se funde com o "saber") e tende a ver outras visões de mundo a partir dessa configuração. Ou seja, quando buscamos uma alternativa só reconhecemos o que cabe no nosso modo de relação com a existência (onto-metafísica), e acabamos "enxertando" (AHENAKEW, 2016) outras epistemologias na onto-metafísica moderna dominante (o que normalmente se traduz em extração, consumo, instrumentalização e apropriação de outras cosmologias).

A outra resposta é a de que, muito antes de querermos entender outras epistemologias, precisamos dar conta dos limites cognitivos, afetivos e relacionais da onto-metafísica na qual fomos hipersocializados. Nesse caso, o que precisamos "entender" são os limites e as implicações de uma maneira de entender que se vê como universal/ilimitada e que não consegue sozinha (utilizando somente a crítica) desfazer esses limites. Em outras palavras, precisamos entender não só que não entendemos ("ainda"), mas que não temos a capacidade de entender (outras maneiras de existir e a existência em si) precisamente por causa do apego (afetivo) à universalidade e do modo (relacional) de existir - não só de pensar - normalizado pela modernidade/colonialidade. Nesse contexto, o processo pedagógico não é o de tornar visível o que a modernidade invisibilizou, mas sim tornar essas invisibilidades visivelmente ausentes (interrompendo o desejo de entendimento universalista) (AHENAKEW, 2016). Esse modo de des-arrogantização é necessário para que possamos aprender sobre o que a onto-metafísica da modernidade/colonialidade nos priva.

A partir daí, em um processo longo e lento, podemos começar a desfazer os modos de relação nos quais essa ontometafísica está baseada. O trabalho nessa beirada-limite se faz através do descentramento do ego, do desentulhamento afetivo (compostagem de inseguranças, projeções, apegos, ilusões, traumas, neuroses e mecanismos de fuga) e do desinvestimento nas satisfações e seguranças que a onto-metafísica moderna/colonial proporciona. $\mathrm{O}$ texto que eu tenho trabalhado com a artista Dani d'Emilia que ilustra um pouco esse processo é "Co-sentindo com ternura radical": http://lapubli.online/TernuraRadical.html. É importante lembrar, porém, que esse processo pedagógico não pode ser somente abstrato e conceitual, ele necessita mexer com as paisagens afetivas e as configurações relacionais para mover configurações de desejo sem coerção (SPIVAK, 2004). Assim, não adianta escrever ou falar sobre a ternura radical. Ao invés de descrever e explicar, precisamos tentar criar experimentos sensoriais e com a terra para que as pessoas possam "sentir" (em vários sentidos) e reativar as capacidades e disposições afetivas e relacionais que foram exiladas pela modernidade. Alguns exercícios criados coletivamente (com paisagens de som) podem ser acessados (em inglês) aqui: https://decolonialfutures.net/rt-recording/

Nesse sentido, vale lembrar que, no coletivo SRFD, a partir de literaturas e práticas indígenas, nós afirmamos que o problema da modernidade não é essencialmente de informação ou conhecimento, mas sim de um hábito danoso de "ser" que é onto-metafísico, tanto consciente quanto inconsciente (ex. vontades, apegos, desejos, projeções, expectativas), e que não pode ser interrompido somente pelo pensamento. Assim, questionar o projeto da modernidade pode ser imprescindível, porém é, na maioria das vezes, insuficiente para reduzir a violência. Talvez a violência só possa ser abordada efetivamente quando muitos de nós tivermos ativado uma capacidade relacional e responsabilidade visceral (que não dependa de escolhas intelectuais e que se sobreponha a interesses pessoais) que reorganizem nossas paisagens afetivas e configurações relacionais para além de desejos e esperanças coloniais.

A partir das vivências com as comunidades indígenas, passamos a ver isso como processos neurobiológicos. Partindo também de estudos científicos sobre práticas indígenas enteogênicas (de alteração de consciência) que utilizam plantas psicoativas que estimulam a produção de serotonina (o neurotransmissor que nos dá a sensação de 
conexão com o metabolismo maior do planeta) e a neuroplasticidade, formamos uma "metáfora-hipótese" sobre como a modernidade/colonialidade condiciona o inconsciente social/coletivo. Na nossa metáfora-hipótese, a modernidade pode ser vista como fomentadora de uma configuração neuroquímica e neurofuncional em que a produção de serotonina é comprometida (e assim nos sentimos separados do todo) e o bem-estar é atrelado a economias intelectuais, afetivas e relacionais que são avivadas pela dopamina (neurotransmissor responsável pelo sentido de conquista), a oxitocina (responsável pela formação de relações transacionais projetivas), pela endorfina (entorpecedor) e pela adrenalina (senso de transgressão e ousadia). Quando levantamos essas questões neurobiológicas, é importante ressaltar que existem riscos reais de redução e simplificação, mas, como metáfora, isso nos ajuda a perceber que existem modos de existência (possíveis e existentes) calcados em outras configurações neurobiológicas - outros modos de bemestar, de bem viver e de "bem morrer" que podem ser viáveis, mas que não temos condições de imaginar a partir da configuração supostamente universal da modernidade/colonialidade. Por isso falamos sobre a necessidade de uma "neurogênese" coletiva, para além das configurações neurobiológicas e psicoafetivas que são autorizadas e fomentadas dentro da modernidade/colonialidade (ANDREOTTI, 2019). Uma explicação mais detalhada em português pode ser encontrada aqui: https://youtu.be/ZTbGHig9LNI

5. O que seria "ativar uma capacidade relacional e responsabilidade visceral"? Como elas podem ser independentes de "escolhas intelectuais"? Você estaria aqui recorrendo a uma suposta separabilidade entre razão (intelecto) e emoção (coração)?

Vanessa Andreotti: Essa é uma pergunta importante, mas a resposta é longa e vem em duas partes. Primeiro a questão da razão e da emoção. Por mais que a gente queira acreditar que pensa "fora da caixa", os nossos parâmetros de inteligibilidade são cerceados por uma gramática de pensamento que localiza o alicerce do ser no "saber", o que atrela a crítica a um ciclo vicioso. Um bom exemplo disso é exatamente a dualidade cartesiana que faz a distinção entre a razão e a emoção. Ao criticarmos a dualidade cartesiana através da dialética, repetimos a dualidade porque precisamos da distinção entre dualismo e não dualismo (que também é um dualismo). O que é descartado (como inexistente) por essa dualidade, o que é impensável quando fazemos essa distinção é, por exemplo, a noção de que existem diferentes sentires que não são nem razão, nem emoção, pois essas são categorias abstratas sem referentes objetivos. No coletivo, chamamos de "analética" (em contraposição à dialética) a observação dos regimes discursivos, relacionais e afetivos de visibilidade, inteligibilidade, relacionalidade e almejamento que fazem o cerceamento das fronteiras do que consideramos real, desejável e imaginável e que determinam o que é descartado pela dialética (AHENAKEW et al., 2014; ANDREOTTI, 2019; MIKA et al., 2020).

Por exemplo, várias etnias indígenas se relacionam com o pensar (atribuir significado) como um "sentido" (de fazer sentido) no meio de inúmeros outros "sentidos" ou "sentires" (enquanto processos sensoriais de receptividade e interação). Porém, na onto-metafísica da modernidade, aprendemos a somente dar importância e a registrar o que "faz sentido" (só é significante o que carrega significado). Essa tendência inibe e atrofia nossas outras capacidades sensoriais que não são registradas em codificações inteligíveis dentro da onto-metafísica moderna. Podemos fazer uma analogia com o sentido do olfato: o sentido do olfato dos cães computa várias informações, incluindo estados afetivos, doenças, situações de perigo e mudanças atmosféricas. A maneira moderna de entender a redução do sentido do olfato humano é através da ideia de "evolução", entendida como "melhoramento" de uma maneira de existência (humana) avançada e excepcional, o que coloca o sujeito moderno como ápice da evolução humana. Outra maneira de enquadrar essa redução olfativa é como uma atrofia, uma perda de acuidade sensorial causada por um modo de existência (moderno) limitado e limitante. Porém, quando eu falo de "sentidos" não estou me referindo apenas à visão, audição, paladar, olfato e tato, mas aos inúmeros "sentires" (enquanto processos metabólicos) dos nossos corpos individuais e coletivos (humanos e não humanos) que acontecem todo o tempo (ou que se encontram atrofiados), mas que a modernidade não registra como "existentes" porque não são articulados em significados (MIKA, 2017).

Além da dualidade cartesiana e da dialética, a gramática da razão moderna também tem outras diretrizes que condicionam a inteligibilidade do pensamento, como o logocentrismo (utilização da linguagem para indiciar a realidade), o universalismo, o antropocentrismo, o alocronismo (ligação entre tempo linear e superioridade racial), a busca da maximização da utilidade (cálculo dos benefícios pessoais) e da teleologia (um lugar predeterminado de chegada). No coletivo SRFD chamamos essa gramática de "BOXHEAD" (ANDREOTTI, 2016, 2019; AHENAKEW, 2016). Como já mencionei anteriormente, com essa gramática da razão vem uma paisagem afetiva 
também condicionada (porém não "determinada") pela modernidade que envolve medos, desejos, expectativas, negações, neuroses, fantasias, promessas e esperanças. Apesar de cada indivíduo ter uma paisagem diferente, o solo que dá sentido/significado e contornos a essa paisagem vem de referenciais onto-metafísicos que são produzidos de maneira coletiva, histórica e sistêmica.

Voltando à pergunta inicial, a responsabilidade visceral depende de outra maneira de ser não encalcada no significado, mas sim no entrelaçamento (não depende de valores, princípios, escolhas ou conveniências contextuais). No coletivo, o exemplo mais concreto inteligível que tivemos foi em uma visita ao Peru. Éramos dez pessoas esperando para atravessar uma rua movimentada, quando um cachorrinho decidiu atravessar sem olhar. A reação das pessoas do grupo foi muito interessante: alguns colocaram as mãos nos olhos, nos ouvidos, na boca; houve um grito... mas uma pessoa, sem fazer o cálculo racional, se colocou no meio dos carros em alta velocidade e conseguiu parar o tráfego para o cachorrinho passar sem problemas. Após o incidente (que deixou todos com o coração na mão), essa pessoa (do nosso grupo) nem lembrava do que havia passado, simplesmente continuou seu caminho, como se nada tivesse acontecido.

Nesse exemplo, a pessoa que parou o tráfego não teve tempo de "pensar", ela usou vários "sentires" tanto individuais quanto coletivos que estavam em ebulição naquele momento para fazer o que fez, sem fazer isso como um ato heroico, ou com base no autointeresse. Na perspectiva dos nossos parceiros indígenas, naquele momento, ela se conectou com a zona de entrelaçamento que funciona como uma metaconsciência, e fez o que era necessário no contexto (não necessariamente o que ela "queria" fazer a partir do cálculo racional, do comprometimento intelectual ou da conveniência individual). A partir desse incidente, começamos a perceber que exemplos como esse podem acontecer com frequência ao nosso redor sem nenhum registro, pois a modernidade/colonialidade não promove sistemicamente a capacidade de identificá-los.

Quando observamos as pessoas que ficaram imobilizadas em um lado da rua, o incidente também traz à tona o fato de que nossos valores e princípios podem até ser "vividos" coerentemente em tempos de equilíbrio relativo, mas são nos momentos de crise que nossas capacidades e disposições se revelam. Por isso, precisamos de pedagogias que possam expandir essas disposições e capacidades para o enfrentamento das crises que vão se agravar e se expandir, principalmente a capacidade de enfrentar momentos e decisões dolorosos, difíceis, irritantes e pesados sem a imobilização ou os desejos de resgate, validação e conforto. Precisamos de pedagogias que levem à sobriedade, maturidade e responsabilidade relacionais, mas estamos apenas no início desse aprendizado coletivo.

6. Boaventura elogia movimentos como o dos Zapatistas e dos Sem Terra, e propõe que se aprenda com eles um outro tipo de marxismo... Como você entende a proposta dele sobre esse "novo tipo de marxismo"? Será que construir mais uma grande narrativa ou estrutura não estaria fadado ao mesmo fracasso e violência do sistema que temos hoje?

Vanessa Andreotti: Eu acho que é extremamente importante aprender, sim, com os movimentos daqueles que já tentaram diferentes modos de decolonização, mas sem a romantização e idealização desses movimentos e sem esse desejo forte de substituição de grandes narrativas. Boaventura de Sousa Santos (2007) fala sobre uma maneira alternativa de abordar as alternativas. Para mim, essa maneira alternativa deve enfocar nos paradoxos dos movimentos decoloniais, para que possamos aprender com as contradições, com as complexidades, com as falhas, com as incertezas e com os acertos, com muita autocrítica e sem romantizações, idealizações ou apegos ao sentimento de "vanguarda". Isso nos ajudaria a expandir nossas capacidades afetivas e relacionais de lidar com coisas difíceis, desconfortáveis e doloridas sem desejar o resgate e sem investir nossa esperança em utopias autocelebratórias. Nesse caso, também precisamos repensar e amadurecer nosso senso de solidariedade.

\section{Você poderia mencionar e/ou exemplificar o que percebe como "paradoxos dos movimentos decoloniais"?}

Vanessa Andreotti: Um dos paradoxos mais visíveis é o desejo de uma resposta pronta que possa substituir a modernidade/colonialidade. Esse desejo reflete a vontade de convencer os outros de que existe uma alternativa/ metanarrativa "melhor", que possa dar esperança (enraizada em um horizonte pré-determinado) para que as pessoas possam caminhar juntas na direção escolhida (o que leva a idealizações, romantizações, essencialismos, instrumentalizações e consumo de alternativas). Essa configuração, que é crítica à epistemologia da modernidade, 
ao mesmo tempo reforça tanto a epistemologia quanto a onto-metafísica moderna/colonial. Boaventura alude a esse problema quando ele fala da necessidade de pensarmos os conhecimentos através de uma ecologia de saberes e ignorâncias - de conhecimentos dinâmicos e limitados, porém, em outros trechos de seu texto, vejo também o desejo da substituição. Paradoxos e contradições são comuns em todos os textos nessa área, inclusive nas minhas respostas. Isso acontece em parte porque ainda precisamos da gramática moderna para poder "fazer sentido" dentro da modernidade em que habitamos, em parte porque é muito difícil mesmo interromper as paisagens afetivas e configurações relacionais da modernidade/colonialidade. Por outro lado, tem muita coisa sobre esse assunto que não tem como articular na fala ou na escrita (tem que ser "vivido"), mas o que não é articulável na modernidade/ colonialidade é percebido como não existente. Vira um tipo de círculo vicioso.

Outro paradoxo comum é a tendência a querermos "decolonizar" os aspectos da modernidade/colonialidade que nos afetam negativamente, enquanto "deixamos quietos" os aspectos que nos beneficiam. O próprio grupo Colonialidade/Modernidade usa a crítica para o avanço acadêmico a partir de desejos coloniais em instituições coloniais e reproduz modos que podem ser interpretados como patriarcais e até extrativos de engajamento. Silvia Rivera Cusicanqui tem levantado essas críticas ao grupo (CUSICANQUI, 2012; ASHER, 2019; GROSFOGUEL, 2019). No nosso coletivo, temos um artigo que mapeia as circularidades que encontramos mais frequentemente em nosso trabalho pedagógico (STEIN et al., 2020). Nesse artigo, apresentamos o acrônimo "CIRCULAR" (em inglês) com uma lista de desejos que embasam essas circularidades (quase funcionou em português!):

- $\quad[C]$ ontinuidade do sistema vigente ("Eu quero as seguranças e confortos que me foram prometidos!")

- [I]nocência, não implicação na violência ("Porque eu sou contra a violência, eu não participo na violência!")

- $\quad[R]$ e-centramento do autointeresse ou dos interesses de grupo de pertencimento ou identidade ("Como isso vai me/nos beneficiar?")

- [C]erteza, forma de conhecer totalizante e universal com resultados pré-determinados e soluções garantidas ("Eu tenho que saber exatamente o que vai acontecer, quando, como, e exatamente para onde isso vai me/nos levar!")

- $[U]$ nrestricted autonomy/Autonomia irrestrita, em que a responsabilidade é opcional ("Eu só presto contas a mim mesmo ou ao grupo a que pertenço.")

- [L]iderança virtuosa intelectual, política e moral ("Ou só eu ou só quem me representa tem legitimidade para direcionar a mudança." )

- [A]utoridade para arbitrar a justiça ("Eu determino o que e quem tem valor e merecimento e quais direitos, privilégios e penalizações serão distribuídos.")

- $\quad[R]$ econhecimento de retidão e absolvição ("Você não vê que eu sou do time do bem?") (STEIN et al., 2020, p. 54)

8. A situação no Brasil é desesperadora: temos visto a escalada recente da violência de várias ordens, desde a verbal até o feminicídio e mesmo situações de extermínio explícito de populações carentes. Muitas vezes essa violência toda, acobertada e fomentada indiretamente por nossos dirigentes, é tratada por boa parte da população como não importante, como "mimimi" de quem reclama sobre ela. Onde encontrar resiliência para lidar com isso? Se considerarmos que já estamos no "olho do furacão", há tempo para esperar o sistema morrer e para aprendermos com ele enquanto sentimos que ele está nos engolindo?

Vanessa Andreotti: É importante não confundirmos o testemunho das forças da tempestade com a experiência direta da violência. Para quem contribui com a violência é necessário encontrar outros pontos de conexão e para isso vamos precisar de metodologias psicoafetivas (e talvez psicoativas) muito diferentes daquelas com as quais temos familiaridade. Estar no olho do furacão significa ativar capacidades exiladas para sentir, relacionar e agir no mundo (coexistir) de modo diferente, indo além da fundação de separabilidade. Nesse caso, temos que entender que as alegações de que a violência seja um "mimimi" são uma resposta infantilizada do ego (individual e coletivo) protegendo seu palácio e seu trono frente à percepção do destronamento e do desmoronamento de seu abrigo. Brigar pelo trono pode ser necessário a curto prazo para evitar que o ego infantilizado acelere o colapso, porém essa não pode ser a estratégia a longo prazo se o palácio está mesmo a desmoronar. No olho do furacão, ao destronarmos nossos próprios egos e nos comprometermos com um processo de amadurecimento e sobriedade (que envolve o 
desentulhamento afetivo e a neurogênese mencionados anteriormente), estamos dando os primeiros passos para a transformação do ego coletivo. Isso também é necessário para o desenvolvimento do discernimento ao buscarmos outras estratégias de evacuação da casa que a modernidade construiu, que está desabando sobre nossas cabeças, e de desilusão benéfica com as promessas falsas que essa casa nos vendeu.

9. Agora falando em termos de decolonialidade e educação, mais especificamente sobre formação de professores, quais as principais diferenças no processo de formação de professores no Canadá e no Brasil? Estamos pensando não em termos estruturais, mas principalmente em termos do processo educativo, ontoepistemológico, ou melhor, em termos do tipo de profissional que se almeja formar em cada país e o que concretamente se pode formar em cada um dos sistemas...

Vanessa Andreotti: Na minha opinião, o processo no Brasil é, felizmente, de certa forma, muito mais politizado, porque as universidades também são comparativamente mais politizadas, devido ao histórico e ao legado de resistência política na educação superior (ou seja, a relação com o Estado é diferente). Projetos de construção curricular coletiva baseada no letramento crítico, como o que aconteceu no estado do Paraná com as diretrizes curriculares em 20052008, e no Brasil com as Orientações Curriculares para o Ensino Médio (SOUZA; MONTE-MÓR, 2006), por exemplo, são inimagináveis aqui. Por outro lado, a questão indígena no Canadá vem sendo priorizada desde a Comissão de Reconciliação e Verdade que trouxe à tona as atrocidades cometidas nos internatos de assimilação isso a gente não vê no Brasil em relação a violências cometidas contra povos indígenas. No Canadá, as crianças eram retiradas das famílias indígenas aos três anos de idade e eram submetidas a abusos psicológicos, físicos, emocionais e até sexuais. O último desses internatos foi fechado somente em 1996. Desde 2016 é obrigatório o ensino da história indígena do Canadá, incluindo os modos de violência que ocorreram nos internatos. Agora imagine um estudante não indígena de Pedagogia, que cresceu achando que o Canadá é um exemplo de civilidade, multiculturalismo e justiça, tendo que interromper a imagem de seu país, sua autoimagem, e dar conta de ensinar a história que essa pessoa tem dificuldade de aceitar. Isso gera muita resistência e desconforto entre os alunos de Pedagogia que são, em sua maioria, colonizadores brancos ou imigrantes que se beneficiam sistemicamente das crueldades da história recente do Canadá e também do apagamento dessa história. O fato de a Comissão da Verdade ter tido o poder de mudar o currículo escolar no Canadá é positivo, porém a implementação é complicada e bloqueada por resistências afetivas e relacionais. Em comparação, a Comissão da Verdade no Brasil que tratou das atrocidades da ditadura não teve poder suficiente para que os responsáveis fossem punidos, nem fôlego para se manter ativa em seu trabalho após a mudança de governo. Aqui eu trabalho muito pouco com educação de professores, assim pode ser que eu não seja a melhor pessoa para responder a dimensão sistêmica da sua pergunta.

10. Mas então o que você sugere para essas pessoas não indígenas que desejam interromper essa narrativa na qual foram criadas? A inclusão do ensino de história indígena nas escolas canadenses seria uma estratégia, um movimento, uma etapa num processo de decolonialidade na formação de uma outra cidadania no país? No Brasil tivemos recentemente a inclusão obrigatória de história afro-brasileira nas escolas: movimentos semelhantes poderiam acontecer no Brasil em relação à violência da ditadura, à colonização portuguesa e o massacre dos indígenas, por exemplo?

Vanessa Andreotti: Como mencionei anteriormente, a informação em si não leva à decolonização, assim como a cidadania também pode ser interpretada como uma construção colonial. Por outro lado, aprender sobre as violências, apesar de insuficiente, é imprescindível. Porém, muitas vezes, porque pensamos que esse conhecimento em si é suficiente, deixamos intactas as estruturas relacionais, afetivas, materiais e "metabólicas" (a relação dos nossos corpos com o metabolismo da terra) que dão continuidade à colonialidade. Precisamos de uma outra maneira de ensinar e aprender que consiga nos movimentar internamente para a beirada-limite da modernidade/colonialidade sem sentimentalismos ou desejo imediatista de substituição (que leva à extração, à apropriação, ao consumo, etc.). É nessa beirada-limite onde aprendemos as lições da modernidade - tanto os erros quanto os acertos, para podermos fazer somente erros novos no futuro e onde aprendemos a oferecer tratamento paliativo à modernidade/colonialidade perecendo. É também nessa beirada-limite que se encontra o que já é viável, porém impensável dentro da casa da modernidade e, onde, gradualmente, em processo longo, é possível aprender a sentir, relacionar e imaginar de modos 
diferentes para que possamos enfrentar a "queda da casa" de um outro espaço (interno e coletivo) de existência. Porém, não existem soluções prontas ou universais e cada solução testada vai gerar outros problemas. Aprender a ter fé e confiança no caminhar biointeligente, numa estrada longa, de buracos históricos, de valas sistêmicas, de tempestades iminentes e em condições de neblina pesada (sem certezas, sem autoridades estáveis e sem a possibilidade de ver o caminho com clareza) é o primeiro passo nessa longa trajetória.

11. Você acredita que ainda é possível atuar e pensar sobre agência, práxis, violência epistêmica, racismo, justiça social, etc., dentro das nossas universidades, partes de estruturas maiores que parecem sujeitas aos interesses neoliberais e do estado-nação? Se sim, qual o nosso papel enquanto formadoras de professores de linguagens, ou mesmo enquanto pesquisadoras dentro de posições de relativo poder na universidade? Ou não teríamos o poder que pensamos ter, mesmo que sendo relativo?

Vanessa Andreotti: Acho superimportante trazer as questões de violência e insustentabilidade à tona nas universidades até quando for possível. Acho também importante não investir na continuidade desses espaços - ou da universidade em si (incluindo nossos salários e aposentadorias) - como único horizonte de atuação e segurança. Muita gente não se sente confortável com a imagem que eu vou descrever a seguir da universidade, mas, para mim, ela ajuda a entender que estamos dentro de um jogo em que tanto jogamos quanto somos "jogados". Essa imagem é a da transformação da torre de marfim (que já era enraizada no colonialismo) em um Walmart de credenciais (enraizado na colonialidade e no capitalismo). Nesse supermercado, nos foi concedido um corredor de prateleiras nas quais vendemos nossos enlatados críticos (que dependem da demanda do consumidor) - alguns são gourmet, muitos são de custo acessível, alta qualidade e podem, inclusive, ser armazenados fora do congelador por bastante tempo, como por exemplo as análises que questionam a construção das normatividades. Enquanto houver espaço, vamos preencher as prateleiras, mas não podemos nos iludir que os enlatados em si vão mudar o mundo - eles podem ajudar temporariamente, mas precisamos nos preparar para a quebra dessa cadeia alimentar danosa e insustentável. Como Burman (2012) mencionou e as comunidades indígenas com as quais o coletivo SRFD trabalha atestam: não existe um caminho intelectual de decolonização através da razão colonial da academia. Não existe um caminho de escrita que nos remeta para fora da modernidade. Não vamos encontrar na leitura um escape da hegemonia epistemológica que a leitura sustenta.

12. Seria o caso de concebermos outro modelo de universidade? Ou você está sugerindo que nenhuma universidade é possível?

Vanessa Andreotti: Qualquer modelo universalista e totalizante de educação é problemático - e isso também se aplica às alternativas. A ideia da universidade em si é baseada na transmissão e construção de conhecimentos universais. Porém, o ensino e a aprendizagem "profunda", o que podemos chamar de "ensino superior" (o que não é o melhor termo), acontece também fora de ambientes institucionalizados. Assim, por um lado, precisamos experimentar tentativas de criar outras universidades (sem romantizações e idealizações) para podermos aprender com as circularidades e os paradoxos desse processo. Por outro lado, precisamos também rastrear e tentar interromper o desejo de instituições permanentes - de uma universidade infindável - para criar espaço para a possibilidade de outras maneiras de educar e existir.

13. Há algum comentário que você gostaria de acrescentar ou alguma pergunta que você gostaria de nos fazer nesta entrevista?

Vanessa Andreotti: Uma crítica frequente ao trabalho do coletivo SRFD que parte de uma interpretação superficial é a de que o coletivo centraliza e romantiza os conhecimentos indígenas. Nossa resposta é que, enquanto as práticas e vivências indígenas nos inspiram e ensinam a viver e a pensar de modo diferente (porque centram o corpo como extensão do metabolismo da terra), nossa prioridade não é centrar o conhecimento articulado, de qualquer grupo, enquanto substituição, destino ou forma/conteúdo universal. Isso é difícil de explicar (e de entender). Por isso usamos muito as imagens, metáforas e mapas nos nossos engajamentos, incluindo uma imagem importante que vem do Brasil. Em situações de enchente, é somente quando a água "bate na bunda" que temos condições de nadar. Antes 
disso, quando a água ainda está no tornozelo ou no joelho, só podemos caminhar mesmo, com diferentes níveis de dificuldade. As populações indígenas, devido às lutas de sobrevivência frente ao colonialismo e à colonialidade, são "nadadoras" - a enchente nessas populações é causada pelos confortos, seguranças e direitos que os não indígenas usufruem (de modo desigual), e que são cada vez mais precários e escassos. As populações nadadoras não têm como nos ensinar exatamente como vamos nadar nas enchentes que vamos enfrentar em contextos diferentes: não existe uma maneira de nadar que vá funcionar em todas as enchentes. Porém, o que esses povos podem, sim, ensinar é que nosso corpo tem a capacidade de se movimentar na e com a água, e também de respirar e ser água.

\section{CONSIDERAÇÕES FINAIS}

Nesta entrevista, as palavras de Andreotti refletem/refratam os diversos experimentos coletivos e inúmeros projetos realizados por ela e seu coletivo dentro, fora e em parceria com universidades em diferentes países. Tais ações se desenvolvem amparadas por noções compartilhadas pelas comunidades indígenas com as quais trabalha e fundamentadas em ontologias relacionais, bem como no que o coletivo chama de psicanálise decolonial, que olha para a terra como elemento crucial para a vida. Esse olhar crítico, informado, construído por metáforas e prenhe de alternativas criativas à modernidade/colonialidade pode contribuir grandemente para as pesquisas em Linguística Aplicada, sobretudo no que diz respeito ao papel político, crítico e in/transdisciplinar desta área do conhecimento, com foco em questões de linguagem na vida social em sua complexidade.

Diante dos tantos assuntos que nos inquietavam ao nos prepararmos para esta entrevista e dos desdobramentos da pandemia da covid-19 que vivemos desde então, as colocações de Andreotti nos alertam para a necessidade pulsante de nos mantermos em posição de alerta, de questionamento não só daquilo de que discordamos, mas também do que concordamos e do que nos agrada. Tal estado de alerta vem acompanhado da percepção de nossa implicatura na violência da modernidade e da pandemia, com suas "fake news" e "cancelamentos" frequentes.

Torna-se premente, uma questão de sobrevivência até, encarar com seriedade e esperança as possibilidades de futuros que ainda não existem, mas que queremos e podemos construir, como nos inspira Andreotti, ecoando Freire com seu conceito de "inédito viável"4. "Esperançar", a la Freire, é um movimento que, certamente, se faz na linguagem com que trabalhamos na Linguística Aplicada e que, como pudemos ver, oferece suporte às reflexões de Andreotti. Assim sendo, esperancemos.

\section{REFERÊNCIAS}

AHENAKEW, C. (2016). Grafting Indigenous ways of knowing onto non-Indigenous ways of being: the (underestimated) challenges of a decolonial imagination. International Review of Qualitative Research, v. 9, n. 3, p. 323-340.

AHENAKEW, C.; ANDREOTTI, V.; COOPER, G.; HIREME, H. (2014). Beyond epistemic provincialism: de-provincializing Indigenous resistance. AlterNative: An International Journal of Indigenous Peoples, v. 10, n. 3, p. 216-231.

ANDREOTTI, V. (2016). (Re) imagining education as an un-coercive re-arrangement of desires. Other Education, v. 5, n. 1, p. $79-88$.

ANDREOTTI, V. (2019). The enduring challenges of collective onto- (and neuro-) genesis. Lapiz, n. 4, p. 61-78.

ANDREOTTI, V.; STEIN, S.; SIWEK, D.; CARDOSO, C.; CAJKOVA, T.; PATAXO, U.; PITAGUARY, B.; PITAGUARY, R.; HUNI KUI, N.; JIMMY, E. (2019). Sinalizando rumo a futuros decoloniais: observações pedagógicas e de pesquisa de campo. Sinergias - diálogos educativos para a transformação social, n. 9, p. 9-28.

4. De acordo com Paro, Ventura e Silva (2020, p. 15), "o inédito viável representa uma alternativa que não se situa no campo das certezas, mas sim no das possibilidades. Trata-se de uma alternativa construída coletivamente, com base na vivência crítica do sonho almejado, e, portanto, não ocorre ao acaso e nem se constrói individualmente. A distância entre o sonhado coletivamente e o realizado cotidianamente pelos sujeitos é um espaço a ser ocupado pelos atos criadores, visto que "assumir coletivamente esse espaço de criação abre possibilidades para que se consolidem propostas transformadoras e ineditamente-viáveis" (FREITAS, 2014, p. 43 citado por PARO; VENTURA; SILVA, 2020, p. 15). 
ANDREOTTI, V.; STEIN, S.; SUSA, R. (2019). Da casa construída pela modernidade ao micélio saudável. Sinergias - diálogos educativos para a transformação social, n. 8, p. 9-19.

ASHER, K. (2019). Reivindicar la cercanía entre los feminismos poscoloniales y decoloniales con base en Spivak y Rivera Cusicanqui. Tabula Rasa, n. 30, p. 13-25.

BAKHTIN, M. (2010). Para uma filosofia do ato responsável. Tradução de Valdemir Miotello e Carlos Alberto Faraco. São Carlos: Pedro \& João Editores.

BAKHTIN, M. (2016). Os gêneros do discurso. São Paulo: Editora 34.

BURMAN, A. (2012). Places to think with, books to think about. Human Architecture: Journal of the sociology of self-knowledge, v. 10, n. 1, p. 101-120.

CAMERON, D. (1997). Demithologyzing Sociolinguistics. In: Coupland, N. \& Jaworski, A. (ed.), Sociolinguistics: a reader. New York: MacMillan.

CUSICANQUI, S. (2012). Ch'ixinakax utxiwa: a reflection on the practices and discourses of decolonization. South Atlantic Quarterly, v. 111, n. 1, p. 95-109.

DA SILVA, N. R.; SOTERO, A. L. E. (2020). A ineficiência da aplicabilidade na Lei Maria da Penha. São Paulo, Revista Âmbito Jurídico, n. 198, [não paginado].

DERRIDA, J. (2005). A farmácia de Platão. São Paulo: Iluminuras.

FREIRE, P. (2014). Pedagogia dos sonbos possíveis. São Paulo: Paz e Terra.

GROSFOGUEL, R. (2019). Epistemic extractivism: a dialogue with Alberto Acosta, Leanne Betasamosake Simpson, and Silvia Rivera Cusicanqui. In: Sousa Santos, B. \& Meneses, M. P. (org.). Knowledges born in the struggle. New York: Routledge, p. 203-218

HELLER, M.; MC ELHINNY, B. (2017). Language, capitalism, colonialism: toward a critical history. Toronto: University of Toronto Press.

JORDÃO, C.M. Applied linguistics "made in Brasil": a guessing game. In: Silveira, Rosane \& Rodrigues, Alison. Applied Linguistics at Issue: dialogues among Brazilian educators. Florianópolis: Editora da UFSC. No prelo.

MIKA, C. (2017). Indigenous education and the metaphysics of presence: a worlded philosophy. New York: Taylor \& Francis.

MIKA, C.; ANDREOTTI, V.; AHENAKEW, C.; SILVA, D. F. da. (2020). The ontological differences between wording and worlding the world. Journal of Language, Discourse and Society, v. 8, n. 1 (15), p. 17-32.

MIGNOLO, W. (2017). Colonialidade: o lado mais escuro da modernidade. Revista Brasileira de Ciências Sociais, v. 32, n. 94 , p. 1 -18.

OLIVEN, R. G.; GARCEZ, P. de M. (2020). A mudança social se desenrola conflituosamente no terreno da linguagem: entrevista com Monica Heller (Professora da University of Toronto)". $\quad$ Porto Alegre, Horiz. antropol., n. 57, p. 315-359.

PARO, C. A.; VENTURA, M.; SILVA, N. E. K. (2020). Paulo Freire e o inédito viável: esperança, utopia e transformação na saúde. Trab. educ. saúde: Rio de Janeiro, v. 18, n. 1, p. 1-22.

PLATÃO. (2000). Fedro ou da beleza. Tradução e notas de Pinharanda Gomes. 6. ed. Lisboa: Guimarães.

SOUZA, L. M. T. M. de; MONTE-MÓR, W. (2006) Linguagens, códigos e suas tecnologias: conhecimentos de línguas estrangeiras. Orientações curriculares para o ensino médio. Brasília: Ministério da Educação / Secretaria de Educação Básica, 2006.

SOUSA SANTOS, B. (2007). Beyond abyssal thinking: from global lines to ecologies of knowledges. Binghamton University Review, v. 30, n. 1, p. 45-89. 
SOUSA SANTOS, B. (2019). O fim do império cognitivo. Belo Horizonte: Autêntica.

SOUSA SANTOS, B. (2020). A cruel pedagogia do vírus. São Paulo: Almedina.

SPIVAK, G. (2004). Righting wrongs. The South Atlantic Quarterly, v. 103, n. 2, p. 523-581.

STEIN, S.; ANDREOTTI, V.; SUSA, R.; AMSLER, S.; HUNT, D.; AHENAKEW, C.; JIMMY, E.; CAJKOVA, T.; VALLEY, W.; CARDOSO, C.; SIWEK, D.; PITAGUARY, B.; D’EMILIA, D.; PATAXÓ, U.; CALHOUN, B.; OKANO, H. (2020). Gesturing towards decolonial futures: reflections on our learnings thus far. Nordic Journal of Comparative and International Education (NJCIE), v. 4, n. 1, p. 43-65.

Recebido: $1 / 3 / 2021$

Aceito: $12 / 5 / 2021$

Publicado: $17 / 5 / 2021$ 